\title{
The impacts of elicitation context on stated preferences for agricultural landscapes.
}

\section{Dugald Tinch, Sergio Colombo and Nick Hanley ${ }^{1}$}

\section{Abstract}

Statements of willingness to pay (WTP) have been shown to be dependent upon the framing of the hypothetical market. In this paper we investigate the effects of variations in the timing and location of choice experiment questions concerned with conservation of a UK national park, as research involving measurement of psychological wellbeing suggests potential differences for the same individual dependent upon when and where preferences are elicited. We apply the choice experiment technique to the valuation of changes in upland agricultural and semi-natural landscapes in the Peak District National Park in the UK, to investigate whether timing and location of elicitation (context) affects the value associated with changes in ecosystem services under different management regimes. Four treatments are employed - using the same sample of individuals answering the same choice scenarios - to measure WTP ex ante (off site), in situ (on site), and ex post at two different time intervals (off site). We show that our on site (in situ) treatment generates very different estimates of preferences than any of the offsite treatments. That stated preferences associated with environmental goods are so context dependent may have implications for the use of stated preferences in policy analysis in terms of identifying how environmental policy is funded and the divergence in value attributed to sampling different populations.

Keywords: cost-benefit analysis; choice experiments; agricultural landscapes; public goods; national parks, context-dependent preferences.

JEL codes: D61, Q15, Q51

1 Dugald Tinch is the contact author (dugald.tinch@stir.ac.uk). Both he and Nick Hanley are with the Economics Department at the University of Stirling, Scotland. Sergio Colombo is with IFAPA - Area de Economía y Sociología Agraria?Camino de Purchil s/n., Granada 18004?Spain. We thank UK Research Councils' Rural Economy and Land Use programme, ESRC and NERC for funding this work, and two referees for comments on an earlier version of this paper. 


\section{Individuals' Association with Environmental Goods}

For environmental resources, such as the uplands of the UK, individuals have differing preferences based upon their relationship with the resource. A number of studies (see for example: Natori and Chenoweth 2008, Rambonilaza and Dachary-Bernard 2007, Hanley et al 2003, Bonaiuto et al 2002, Jones et al 2000, GomezLimon and Fernandez 1999, Van de Berg et al 1998 and Bullock and Kay, 1997) show divergence in value between groups distinquished by their association to the resource; for example, between locals, visitors and those involved with management of the resource. This "insider-outsider dichotomy" (Jones et al 2000) suggests that values are not uniform over a general population, but rather vary between and within different groups who use, interact with and appreciate the landscape in different ways (Kaltenborn and Bjerke, 2002). Environmental valuation practitioners have spent much time investigating alternative ways of modelling such underlying preference heterogeneity (e.g. Hynes et al, 2008)

An un-explored aspect of this empirical measures of such divergence, however, may be related to the method of preference elicitation. A standard approach would be to identify and survey visitors on site and use off site surveys (postal, internet or door to door) for a defined "local" population. However, work by Kahneman and others (See Kahneman and Sugden 2005) in the behavioural psychology literature shows that the act of experiencing a good impacts on preferences as measured by psychological well-being methods. Given this, we investigate the effects of the timing and location of preference elicitation on willingness to pay. Our premise is that individual preferences are conditioned by context and association, and vary according to when and where an individual's utility is investigated. To our knowledge this is the first time that context in this sense (including both location and timing) has been tested formally in the literature. In the following section we discuss this behavioural literature, before describing the case study used to test the effects of context on agricultural landscape values. Results and a discussion follow. 


\section{Insights from behavioural science on the importance of context: adaptation, ex ante preferences and ex} post well-being.

Conventional welfare economics and the theory of rational choice from which it derives are based on the notion that individuals have a stable and complete set of preferences which they use to make choices ${ }^{2}$. These ex ante choices then reveal the value that consumers place on the choice alternatives (e.g. on different films to buy, or different beaches to visit). However, Kahneman and Sugden (2005) suggest that problems of affective forecasting, (i.e. accurately predicting utility impacts of decisions) mean that peoples' choices based on their ex ante preferences may be biased indicators of actual well-being. ${ }^{3}$ They note that early nineteenth century economics employed a concept of hedonic utility based on an absolute measure of pleasure and pain. Bentham (1789) argued that utility, which he identified as the amount of pleasure or pain associated with an event, was quantifiable and additive. He related levels of utility to the drivers of probability, intensity, duration and extent. Edgeworth (1879) referred to absolute measures of pleasure and pain from which overall happiness measures should be calculated over some time period. The idea of utility as a momentary measure of hedonic experience has become known as experienced utility. However, as Kahneman and Sugden (2005) point out, economics retreated from this concept of utility around the beginning of the $20^{\text {th }}$ century. Kahneman and others' normative approach to the consideration of utility is that "instant utility" gives an absolute measure of the utility (pleasure or pain) we are experiencing at any moment. In part this is related to "availability heuristics" (Tversky and Kahneman , 1982) that is the ease with which an event or scenario can be brought to mind. A summation of instant utility gives us a measure of 'experienced utility' for a given period of time. Either concept may be measured in a number of ways, including the experience sampling method (Stone et al, 1999), and the day reconstruction method (Kahneman et al, 2004). A movement back to experienced utility as a basis for economics is called for, so the argument goes, since anomalies in individual behaviour mean that the idea of individual rationality within a decision utility context becomes a shaky foundation on which to build public policy analysis through, for example, the use of stated preference methods (Hanley and Shogren, 2005). Robson and Samuelson (2010) have recently argued that the dichotomy between decision and

\footnotetext{
${ }^{2}$ An alternative view is that individuals may be unsure about their preferences, and discover them through experience using a Bayesian updating process which reduces preference uncertainty (eg Czajkowski et al, 2013). However, this is a rather different departure from the standard model of preferences and choice than that focussed on in this paper.

${ }^{3}$ Examples of literature which make this argument include Bateman et al 2000, Tversky, Sattath and Slovic 2000, Kahneman 2003, Kahneman and Sugden 2005, Loomes 2006 and Beshears et al 2008.
} 
experienced utility has emerged due to evolutionary pressures in that "..evolution systematically misleads the agent as to the future implications of his choices" (p.2), due to people's inherent inability to correctly choose between rather similar alternatives. Such an analysis takes the distinction between experienced and decision utility as self-evident.

However, most economic analysis of the past 100 years has made use of the concept of decision utility (Kahneman and Sugden, 2005). As noted above for decision utility and experienced utility measures to be equivalent, individuals must be 'affective forecasters' - that is, capable of making reliable judgments about how they will feel in certain future conditions. A growing body of research suggests that this is not the case (Gilbert and Ebert 2002 and Gilbert et al 2004). For example, Dunn et al (2003) find errors in how much happier students think they will be if they realise their preferred choice of university accommodation. Reasons for divergence between predicted well-being and actual well-being (once experienced) include this failure of affective forecasting, adaptation to changes in consumption over time, availability heuristics and focussing effects. Moreover, based on findings reported in Dunn et al (2003), we might expect the relationships between variables thought to determine the satisfaction of certain outcomes and a measure of such satisfaction or wellbeing to differ according to whether people are making predictions about how a particular choice will impact on their well-being in the future, relative to how a choice actually impacts on their well-being as measured at the moment of consumption.

The idea of adaptation of self-assessed well-being to change was first proposed by Helson (1964) and Scitovsky (1976). An alternative with similar implications is that of projection bias (Loewenstein et al 2003). In summary the overall satisfaction individuals anticipate from a particular outcome or situation tends not to equate to the final satisfaction they report once a change has occurred. For instance, individuals get used to a new situation (such as higher disposable income), and factor this into their measures of well-being. Well-being increases due to rising incomes, for example, are thus temporary - the Hedonic Treadmill (Brickman and Campbell, 1971). However, not all goods or experiences are susceptible to similar degrees of adaptation. Scitovsky (1967) identified two types of goods, pleasures and comforts, where, pleasures are not subject to adaptive perception while comforts are experienced relative to context and condition. Of particular relevance here is the suggestion by Kahneman and Sugden (2005) that it is unlikely that individuals adapt to beautiful landscapes, (that they may be pleasure rather than comfort goods) which may suggest that household expenditure on non 
market environmental resources is a valuable way to increase utility. In terms of the current research, adaptation suggests that for many goods (especially those which can be classed as comforts) individuals' values will differ between the moment of consumption (consuming a good or on site/in situ surveys) and moments when a good is not actually being experienced but rather is being considered (purchasing or deciding to purchase a good or off site surveys).

These arguments strongly suggest that we should test whether measures of welfare (in our case, willingness to pay) based on in situ surveys differ from those based on off site surveys, i.e. that welfare measures elicited at the "moment of consumption" will differ from those elicited based on either the anticipation/prospect or on a memory of the experience of an environmental good such as landscape quality.

\section{Study Area and Design}

To perform the tests of context influence on WTP, we designed and implemented a stated preference Choice Experiment in the Peak District National Park, England ${ }^{4}$. We chose a choice experiment so as to obtain estimates of willingness to pay for prospective changes in the characteristics of a public good - agricultural landscape and its associated biodiversity - in three different contexts: ex ante offsite, in situ during a visit onsite, and ex post off site. Four treatments, described in more detail below, were used to determine the effects of these changes in context:

In treatment 1, the survey was administered ex ante and offsite,

In treatment 2, the survey was administered in situ at the national park site in question,

In treatment 3 the survey was administered immediately after this visit, and was thus ex post and off site;

In treatment 4 , the survey was administered some 4 months later offsite.

All the participants were subjected to all of these treatments in our experiment. We aim to identify whether such changes in the valuation context impact upon the stated preferences elicited for a given individual for a given environmental good, by comparing preferences and willingness to pay for attributes across treatments.

\footnotetext{
${ }^{4}$ For details on the choice experiment method, see Hensher et al, 2005. For details on the set of environmental valuation methods available to economists, see Hanley and Barbier, 2009.
} 
The Peak District National Park lies within an hour's drive of one third of the UK's population, and is the most heavily visited National Park in the UK. The focus for our research was the likely impacts of future land management change on landscape and biodiversity values of the area. We focussed on livestock farming as the dominant land use in the area (Dallimer et al, 2009; Hanley et al, 2012). Whilst our focus was on management intensity and associated biodiversity impacts, it is clear that management intensity changes can also affect other ecosystem services in the National Park, in particular the maintenance of drinking water quality, flood protection and recreational uses such as grouse shooting. However, based on the results of a scoping study, these were not included in the choice experiment design.

We focussed on the values of changes to individuals living near, but not within, the National Park itself (as explained below). Although these individuals did not live in the park the main transport routes to and from each of the settlements pass through the National Park and our participants would all see the National Park (i.e. would all see the landscapes being considered by the experiment) on a regular basis, if not from their house window then from the main street of each settlement. The choice experiments were applied through a valuation workshop approach (Alvarez-Farizo and Hanley, 2006) with three locations representative of the local area being chosen for sampling. Valuation workshops were employed to cater for: the need to sample the same individuals at different points in time; the complexity of the public good in question; the extent of information on the implications of management change for this public good which needed to be conveyed to respondents.

Individuals were chosen who lived relatively close to the workshop locations through mail shots, telephone calls, leaflet drops and advertisements in local shops. The choice of sampling locations was constrained by the need to be close to a site in the National Park which contained landscapes representative of the management intensities being considered. The communities chosen for recruiting participants were: Stannington, a large village on the outskirts of Sheffield; Stocksbridge, a former steel and mining town; and Penistone, a market town. The site chosen for the second in situ experimental treatment (onsite) was on the Strines Moor Road, selected as it gave views of all relevant representative land management regimes. Participants were paid $£ 25$ for participation in the first workshop and $f 50$ for participation in a second workshop. In total 52 participants took part. The small sample size was constrained by the need to transport all respondents to the Strines Moor 
Road site, in order to minimise potential sources of bias by ensuring all the other conditions external to the experiment were fixed. Workshops were run in October 2007 and January 2008.

Participants were all local residents not involved in farming and our sample was broadly representative of the local population. However, females were over represented (71\% to $52 \%$ ). Mean age in our sample was 40 whilst the mean age in the population was $46^{5}$. Mean incomes were higher than the mean $£ 13,800$ for the Yorkshire and Humber region, $£ 25,800$ (standard deviation $£ 17,000$ ), since our participants were from relatively wealthy areas within that region. In terms of use of the park, $52 \%$ of the sample visited more often than once every three months and all participants reported that they visited the Peak District National Park at least once a year.

The nature of the experiment meant that participants were asked to complete a large number of choice cards. Respondent fatigue ${ }^{6}$ was a distinct possibility and participants were encouraged throughout to consider carefully every choice they were making. From observations at the time of the experiment it was clear that most, if not all, of the participants were paying close attention to each choice and referencing the additional material provided (posters and handouts summarising the information given) at regular intervals. No specific question was included on attribute non-attendance. As each of the experiments contained 16 choice cards, this gave 832 choices for each experiment ${ }^{7}$.

\subsection{Treatments used}

Four treatments were used in this study. By "treatment", we mean a choice occasion when data is collected from the same set of individuals under different circumstances. Each treatment thus involved respondents in completing a set of choice cards from the same underlying experimental design, all representing the same

\footnotetext{
${ }^{5}$ Due to data availability for the local population these means had to be extrapolated and are representative of Peniston and Stocksbridge parliamentary seat - thought also to be broadly representative of the population of Stannington

${ }^{6}$ Risk of invalid response due to excessive demands being placed upon the research participants.

${ }^{7} 70 \%$ of respondents answered all choice cards in the 4 treatments. Of the remaining $30 \%$, half did not come back for the fourth treatment (remembered utility), held four months after the first. To increase comparability across treatments all the choices, these individuals were omitted from the analysis, leaving a total of 672 observations for model estimation ( 2 individuals did not report their socioeconomic characteristics and were also omitted). The other $15 \%$ answered a subset of choice cards in some of the 4 treatments (see table 2 for the exact number of observations in each treatment) and were retained in the analysis. These omissions predominantly related to marking more than one choice and deletion leading to a level of uncertainty over choice. Analysis including these omitted choices did not materially impact on the findings of the research.
} 
range of changes in landscape and biodiversity in response to changes in management intensity. Each individual responded to identical choice cards in each treatment and the same information was given relating to the attributes of the choice experiments prior to each treatment. The same visual information in the form of posters showing different management regimes and bird species were also visible during each treatment.

Treatment 1 (ex ante) gives our baseline estimate of willingness to pay for different levels of landscape change in the Peak District National Park. This experiment was run in a local community centre prior to a visit to the national park. This treatment represents the value estimated in most choice experiments (and other stated preference techniques), since it is based on information given to participants through description, visual images and orally. It is not, however, provided at the "point of consumption".

Treatment 2 (in situ) was conducted on-site where a representative series of landscapes could be seen (in addition to the description and visual images). Participants were driven by minibus into the Park, and shown the landscape characteristics which they were valuing in the choice experiment. They were able to leave the minibus to look at the landscape although most returned to sit down prior to completing the choice cards. Individuals could identify the impacts of management changes without needing to rely on their own anticipation of landscape changes. Participants were shown landscape features characteristic of each proposed level for each management attribute, and were asked to identify those features relevant to the combinations presented in the choices before them. The two adjacent areas to the site involved intensive and extensive moorland fringe management practices whilst areas of intensively and extensively managed moorland backed onto these. Below the site was a panorama showing intensive and extensive management of farmland rising across the valley to additional examples of moorland fringe and moorland management.

Treatment 3 (ex post 1) was conducted upon return to the community centre on the same day as the site visit (within 15 to 30 minutes of the completion of treatment 2).

Treatment 4 (ex post 2) was administered during a second workshop held in the same community centres four months after the first. 
The choice experiment was developed with colleagues from the Department of Animal and Plant Sciences, Sheffield University, who provided inputs on the likely impacts of management change on the Peak District National Park. This information was based on data collected and experience developed through a wider project investigating the likely impacts of changes to agri-environmental schemes on management practices and the resultant impacts on bird diversity (Armsworth et al, 2012). In order to design the experiment, a series of focus groups were organised, as well as a pilot study. All policies under consideration were changes to agrienvironmental schemes to reduce or increase management intensity, but not to abandon farmland. In relation to biodiversity impacts respondents were told that less intensive management would lead to a greater variety of habitats and species. It was made clear to participants that more species did not mean a greater number of total birds, or any greater chance of seeing birds.

The choice experiment design included five attributes: intensity of management in three habitat areas moorland, moorland fringe and valley bottom farmland; footpath network quality; and annual household tax increases. These attributes were explained to respondents at the start of Treatment 1 (and again prior to each treatment in order to maintain consistency between treatments). Each landscape attribute (moorland, moorland fringe, farmland) was matched with a number of representative bird species to represent likely impacts of management on biodiversity, as detailed below. Participants were given a verbal description of the attributes in question and two posters were presented: one giving pictorial information about landscape intensity; and the other one consisting of photographs of representative bird species and footpath quality see below. The same verbal description was given to participants prior to each treatment and the same posters were visible.

Moorland Management Intensity was set at three possible levels (More Intensive, No change in Intensity, Less Intensive). The intensity of management on the moorland areas currently varies across the national park. More intensive moorland management was represented by increased numbers of sheep and moorland burning. Burning of moorland encourages young shoots to grow which also leads to increased numbers of grouse for shooting. Less intensive management was depicted as having the opposite impacts. Representative moorland bird species shown to respondents in the survey materials were: the golden plover (Pluvialis apricaria), merlin (Falco columbarius), dunlin (Calidris alpine) and short eared owl (Asio flammeus). 
Moorland Fringe Management Intensity - this also took three levels (More Intensive, No change in Intensity, Less Intensive). More intensively managed moorland fringe can resemble in-bye farmland, with sufficient fertiliser input to produce lush green fields, with increased sheep numbers. Less intensive management leads to more scrub-like appearance with occasional shrubs. The moorland fringe area is relatively important for biodiversity since it is a transitional zone providing resources to both moorland and farmland species in addition to habitat specific and other species. Representative moorland fringe bird species used were: the reed bunting (Emberiza schoeniclus), stone chat (Saxicola torquata), wheatear (Oenanthe oenanthe) and lapwing (Vanellus vanellus).

Valley Bottom Farmland Management Intensity - three levels were again used (More Intensive, No change in Intensity, Less Intensive). These valley bottom farmland in the Peaks are the "traditional" green fields of the English countryside, found in the Peak District at lower altitudes bordered by dry stone walls. More intensive management results in greener fields with more sheep, with less intensive management having the opposite impact. It was made clear that field boundaries and buildings would continue to be maintained whatever the management regime adopted. Representative bird species used were the yellow hammer (Emberiza citrinella), linnet (Carduelis cannabina), redstart (Phoenicurus phoenicurus) and pied flycatcher (Ficedula hypoleuca).

Footpath Network Quality - three levels were used for this attribute (Improved, No change, Degraded). The quality of the footpath network with a degraded state was represented by an increase in the length of footpaths with more degraded sections (eroded and muddy) and an improvement represented by an increase in the number of paths managed to prevent degradation.

$\underline{\text { Tax }}$ - six levels selected based on average council tax in the areas, shown as additional tax burden to the household per year.

A business as usual baseline based upon likely future landscape change was included in the design. Estimates of the impacts on the park if no additional money is made available identify the likelihood of an increased management intensity in all areas and a degradation of the footpath network. As such, the baseline (zero cost) option available to participants for every choice set presented was increased management intensity of all landscape areas (moorland, moorland fringe and farmland), a worsened footpath network and zero additional 
tax cost. The options which this baseline was set against were developed using a fractional factorial orthogonal design ${ }^{8}$, with two alternative choices being presented on each choice card (see Table 1 for a sample choice card). The same additional verbal information was given prior to each treatment detailing the information presented above, while individuals were encouraged to ask questions in order to clarify the information they had received prior to the first treatment. This facility was obviously also available to participants prior to each treatment but other than clarifying questions on site (e.g. "So that is more intensive / less intensive?") no additional questions were asked in subsequent treatments. To enable participants to become familiar with the process involved in making a choice, a series of practice sample choices were presented and explained prior to undertaking the first choice tasks.

\section{Results}

Initial analysis of results used a conditional logit specification (Hensher et al, 2005). Some models, however, failed the Hausman test for IIA (independence of irrelevant alterntives) so an alternative specification was required. We found that both the nested logit model and error component model provided good model fits. The Error Component model is an evolution of the Nested Logit model and the results of this specification are presented here. The error component model allows flexible patterns of substitution via induced correlation across utilities, which relaxes the IID assumption of the multinomial logit specification (Scarpa et al, 2005) in that it allows for correlation of the unobservable portions of the utility of alternatives. The model can be defined as:

$$
U_{n i}=\beta^{\prime} x_{n i}+\varphi^{\prime} \eta_{n i}+\epsilon_{n i}
$$

Where $U_{n i}$ is a measure of utility for alternative $i$ and respondent $n, x_{n i}$ and $\eta_{n i}$ are vectors of observed variables relating to alternative i, $\beta$ is a vector of fixed parameters, $\boldsymbol{\varphi}$ is a vector of random terms with zero mean. That is $\eta_{\mathrm{ni}}$ are the error components that, along with $\epsilon_{\mathrm{ni}}$, make up the unobserved portion of utility.

In the context of this study, we introduce correlation terms in the utility specification of the two "policy on" options (option A and B in table 1), to gather unobserved common elements of the respondents' choices for

\footnotetext{
${ }^{8}$ The attributes and levels used in this study forms a full factorial design of 486 alternatives which were reduced to 16 using a main effect experimental design. The design finally used was chosen according to its $D$ efficiency $(0.26174)$ and the absence of dominated or irrational alternatives in the 16 choice cards.
} 
these options relative to the status quo option. We emphasise that the results presented below are derived from the same participants responding to identical choices in repeated experiments (treatments). So whilst there are alternative modelling approaches which permit a different treatment of preference and scale heterogeneity (both observed and un-observed), the error component model is appropriate here, since our focus is on the effects of changes in context on mean preference parameters and on implicit prices ${ }^{9}$.

Table 2 shows the estimated coefficients for each treatment, Table 3 identifies the coding used and Table 4 shows the implicit prices (willingness to pay) calculated for landscape change away from the (deteriorating) baseline in each treatment. A range of socioeconomic variables (which include per capita income, the number of children, whether respondent or a household member was a recreational user of the national park, etc.) were initially incorporated in the choice model analysis. Sex and age, however, were the only characteristics significant in at least one treatment. The regression coefficients of these characteristics in Table 2 suggest that women and older individuals are more likely to choose either option A or B over the status quo.

The estimated parameters in each treatment are confounded with an unknown scale parameter which is inversely proportional to the error variability of the respondents' choices in a particular treatment (Colombo et al 2007, p. 137) $)^{10}$ This is true despite the fact that our analysis was based upon the same individuals answering the same choice cards in each treatment. Because of this, before commenting on the results of the individual treatments, we present the results of a pooled model where we fix the scale parameter of the first treatment to one and allow the scale parameters of the other treatments to vary. Estimated coefficients and scale parameters of this pooled model are shown in the last column of table 2.

Due to the larger sample size most of the coefficients in this pooled model are significant. The interesting result which emerges from this analysis is that for all landscape types respondents show an aversion towards changes in landscape management, no matter whether the change involves more intensive or less intensive management. The only attribute where respondents prefer a change to the status quo (more intensity and deterioration in footpaths) is for an improvement in the footpath network. The analysis of the relative scale

\footnotetext{
${ }^{9}$ The low sample size does not allow a robust estimation of models which expressly consider individual taste heterogeneity. We acknowledge that this may be a limitation of the study, given that landscape preferences are known to be heterogeneous (Campbell 2007, Grammatikopoulou et al., 2012)

${ }^{10}$ The estimated parameter $\left(\beta_{\mathrm{e}}\right)$ is linked to the true parameter $\left(\left(\beta_{\mathrm{t}}\right)\right.$ with the following relation: $\beta_{\mathrm{e}}=\left(\beta_{\mathrm{t}}\right.$ * Scale). Scale is the scale parameter which is inversely proportional to the error variance.
} 
parameters reveals that context has a significant impact on the scale parameter (the relative scale of Treatment 2 is almost half of the scale of Treatment 1 and it is statistically different at the 95\% confidence level). Since the scale parameter is inversely proportional to the variance of the error terms, this suggests that the context of being onsite increases the variance of the error term. In other words, when respondents are actually observing the landscape features described in the choice cards on site, they find it more difficult to choose between the alternatives. It is interesting to observe that the scale parameter of the choices of Treatment 3 and 4 are not significantly different from the scale parameter of Treatment 1, showing that the significant changes in the randomness of individual choices is only experienced onsite and not from the memory of a visit.

A second important result is that changes in context affect the parameter estimates of the tax attribute and the constant. Respondents did not focus on the price associated with the proposed alternatives in Treatment 2, unlike all other treatments. Again, we attribute this fact to the sensation that respondents feel when they are asked to choose their preferred alternative when they are actually facing the different landscapes "in person". Individuals make their choices paying little or no attention to the price attached to the alternatives in an onsite context, but focus instead on the landscape characteristics they most prefer. As was discussed above the behavioural psychology literature would suggest that this is not an unexpected result in the moment of experience given the issues of focussing effects, availability heuristics and affective forecasting. Respondents focus on those attributes which are available and visible onsite rather than those which are not present in the environment (tax and footpath attributes).

In spite of the difference in relative scale across treatments, it is possible to compare Willingness to Pay (WTP) measures across treatments, since the scale parameter cancels out in the implicit price calculations (Scarpa et al. 2008). Table 4 presents the willingness to pay estimates. It is interesting to note that estimates for all WTP amounts (those that are significantly different from zero) for management intensity coefficients are negative, not positive. The analysis calculates WTP for a shift away from the current management system (no change in management intensity). The results thus suggest that, independently from the conditions in which they were asked to make their choices, individuals are willing to pay in order to avoid a future level of management which is more intensive in character, although for moorland fringe the $95 \%$ confidence interval for WTP spans zero. Additionally individuals are willing to pay (in general) to avoid a less intensive management regime in the 
habitats, although again this is not significant in some treatments. The implication is that there appears to be a significant status quo preference, since individuals would be willing to pay in order to maintain current levels of management intensity. This preference for the status quo has been observed in other stated preference studies of UK national parks (e.g. Hanley et al, 2008). We now provide more detailed comments on each of the four treatments.

\section{Treatment 1 - Ex Ante}

In this treatment, individuals have the highest WTP to avoid more intensive management in the moorland areas and valley bottom farmland habitats. This is perhaps unsurprising as whilst valley bottom farmland makes up a relatively small proportion of the park (as opposed to moorland habitats) most roads in the park run through valley bottoms and this landscape is seen from representative images presented of the National Park on tourism websites to be archetypal of the Peak District National Park. These landscape attributes are therefore expected to be important for respondents in their ex-ante preferences. Respondents are also WTP to avoid a reduction of the management intensity in the moorland fringe and valley bottom farmland and prefer an improvement of the footpath network.

Treatment 2 - In Situ

This is the poorest fitting model of the four treatments and also showed a higher variance of the error terms, which implies that respondents, when visually faced with the landscapes, feel less sure about their preferred landscape. A possible explanation is that there are a set of other factors, not contemplated by the attributes used in the choice cards, which are influencing their choices and confusing preferences for landscape attributes. This is also confirmed by the significant alternative specific constant, ${ }^{11}$ which is only significant in this treatment. The most striking impact of being on site is on the parameter estimate for the tax attribute, which is not significant in this treatment. Due to the insignificance of the parameter of the tax attribute, it is not possible to calculate marginal WTP in this treatment. Relative to the coefficients of treatment 1 , being on site and experiencing the landscape significantly affects the preferences for less intensive management. In all attributes, save the footpath network, the switch to less intensive management reduces the respondents'

\footnotetext{
${ }^{11}$ The significance of the constant reveals that in this treatment respondents are more likely to choose "policy on" alternative for other reasons not explained by the attribute used in the choice cards.
} 
utility. This is particularly true for moorland, where less intensive management becomes significant with a large coefficient ${ }^{12}$. Along the same lines, being onsite modifies the preferences for the moorland fringe landscape and less intensive farmland management. It is interesting to note that context does not impact significantly the preferences for more intensive management. For instance: the coefficient for the moorland more intensive attribute, once the differences in scale are taken into account, is practically the same in treatments one and two; the coefficient of moorland fringe intensity remains insignificant in both treatments and the valley bottom farmland intensity coefficient does not show significant differences. The improvement of the footpath network is no longer considered important by respondents.

The same choice cards (same experimental design), albeit with a different payment vehicle, were used in a subsequent on site experiment involving visitors to the national park where it was found that improvement to the footpath network was significant and positive suggesting that this result is only found in situ for those residing close to the national park. From the lack of significance of the price variable, results for the footpath network and significance of the constant it can be concluded that individuals are basing their decisions predominantly upon the variables which they can directly observe - other variables which cannot be experienced at that moment (footpaths and cost) are being paid significantly less attention than when individuals are not faced with the landscape characteristics directly.

Treatment 3 and $4-$ Ex Post

The fit of these models is very similar to treatment 1 , although there are changes in parameter values for the choice attributes. In these models the only significant attributes are the more intensive management of moorland and farmland. Relative to treatment 2 the most striking result is that the impact of less intensive managements of the landscape is no longer important for respondents. It is surprising that even in treatment 3, which was administered as soon as respondents returned from their field trip, all the attributes which describe a less intensive management are no longer significant. This is possibly a manifestation of the effect of context on the preferences for intensity of management - with individuals taking away a focus on more intensive management from their experience of visiting the landscapes. Focusing on the values of the

\footnotetext{
${ }^{12}$ Note that to compare the value of the coefficients it is necessary to take into account the value of the scale parameter. For instance the value of the less intensive moorland management coefficient of treatment 2 relative to treatment one will be -0.977 resulting from dividing the estimated coefficient $(-0.506)$ by the estimated scale parameter (0.518). The same applies for the other coefficients.
} 
significant coefficients, again after taking scale into account, coefficients are larger than in the previous treatments, showing less aversion towards more intensive management. However, in treatment 4, which was administered four months later, their values are very similar to the ex-ante value, suggesting that the on-site "focus" on more intensive management in the landscape is temporary (prompted by visual experience). However, preference for no change in intensity over more intensive is consistent across time albeit at different levels.

Focusing on the monetary attribute, being onsite led respondents to ignore the tax associated with the chosen alternative. In treatment 3 the marginal disutility of the tax is again significant but with a lower value relative to the ex-ante value. This suggests that respondents, having just experienced the landscape, put less importance on the monetary attribute. Four months later, the marginal disutility of the cost attribute increases again, and is even higher than in the previous treatments. As discussed below this could in part be related to the impact of the world financial crisis impacting on consumer spending patterns between treatments 3 and 4 .

With the exception of improving the footpath network, all mean WTP estimates decrease in absolute terms for maintaining current management levels in the third treatment, although they do not differ statistically from the estimates of treatment 1 . Recall that this third treatment was administered as soon as respondents returned from their field trip. By the fourth treatment, administered 4 months later, mean WTP estimates for changes in farmland continue this trend relative to treatment 1 , showing that respondents are less WTP for maintaining the current landscape management.

\section{Discussion and Conclusions}

It has been known for some time in valuation research that the framing of the environmental good, in terms of how the hypothetical market is designed and conveyed to respondents, can affect stated willingness to pay (Hoehn et al, 2010). These effects, such as changes in the information provided to respondents and changes in the payment vehicle, have been noted by several researchers (see, for example, Munro and Hanley (2002)). This paper aims to identify a rather different effect of context, which relates to some recent findings in behavioural sciences, and investigates whether valuations elicited before, during or after the "moment of consumption" of the good being valued differ, and whether valuations obtained off-site or on-site also differ. If the location and timing of preference elicitation materially affects our measures of individual preferences for 
and willingness to pay for environmental goods, then this creates awkward questions as to which measure is correct for applied cost-benefit and benefit transfer analyses. We find that the timing and location (context) of identification of preference for a given environmental resource (given the same sample, experimental design, choice cards and methodology of application) does have an impact upon the resulting stated preferences for landscape characteristics. In particular, we find big differences between "moment of consumption" measures of preferences and willingness to pay (treatment 2) and either anticipated (prospective) (treatment 1) or retrospective consumption (treatments 3 and 4). Whilst there are many possible causes of these variations across treatments - such as variations in information and experience which individuals bring to the experiment - the differences are striking. In particular treatment 3 was carried out within 30 minutes of treatment 2 (and in most cases within 15 minutes) so the "information" individuals received during treatment 2 was still fresh in their minds. This result also suggests that practitioners should consider the location and timing of preference elicitation in assessing whether results are comparable with or transferable to alternative sites.

We used a choice experiment approach to measure the effects of changes in the location and timing of preference elicitation. The capacity of choice experiments to reveal consistent preference for environmental goods with the same (or similar) content but different timings, i.e. temporal stability / validity / reliability, has previously been tested in the literature. Bleim et al. (2012) tested preference for river management in an experiment conducted in both 2007 and one year later in 2008. They found that preference and willingness to pay estimates for programme attributes are robust i.e. not sensitive to time. This research relied on two separate samples in the different time periods. Liebe et al (2012) adopted a test/retest survey administered 11 months apart (2008 and 2009) to the same individuals in two time periods for onshore wind power in Germany. Again they found willingness to pay results to be relatively consistent between the surveys. This evidence of temporal stability again is indicative that the divergence observed in the current study is indeed a result of context rather than timing.

An interesting analogy between the research presented here in terms of the impacts of location and timing (context) on estimates of preferences for environmental goods can be found in the behavioural psychology literature. Our findings may also be of relevance in answering the debate over whether an economic 
approach can be taken to the investigation of moment based utility, as debated by Kahneman and Sugden

(2005). Our results indicate that, for environmental goods, the results often shown through lab experiments in the psychological literature may be found to hold in the field ${ }^{13}$.

It was not possible to make definitive statements about the causes of changes in measured preferences between treatments due to a relatively small sample size and relatively high standard errors, and to an inability to control for other factors than location and timing that may have varied across treatments. There are, though, suggestive trends in estimated coefficients between the treatments: willingness to pay is typically higher (in absolute terms) in treatment 1, and falls in treatment 3 and 4 . However, the most striking result is the lack of significance of the tax attribute in the on site treatment, despite its strong significance in all other treatments. When people are experiencing the good in question (here, the landscape quality of a national park), they modify their marginal utility of income so that their choices are no longer affected by the cost involved in achieving the desired outcome. A possible explanation if that the monetary levels used did not vary over a sufficiently wide interval, so that they did not effectively constrain respondents from choosing their preferred (visual) landscape. This may happen because, as is normal in the choice experiment literature, the level of the monetary attribute was designed according to focus group and survey pre-tests made ex-ante the experiment. This result is a warning of the importance of considering a wider interval of the monetary levels in stated choice experiments, even where analyst thinks that pre-testing off site has provided suitable levels, since our results suggest that context may alter respondents' valuations substantially.

It is also possible that the on-site experience of treatment 2 effectively enhanced people's information sets, and thus changed their preferences. There has been much research in stated preferences into the effects of changing the information provided to respondents (e.g. Munro and Hanley, 1999). Tversky and Kahneman (1982) have argued that the availability heuristic is an important influence on how people choose or assess alternatives: being on-site may have operated in this way, by enhancing the effectiveness of the information provided in all treatments, whilst actually seeing the landscape features which were part of the experimental design would also enhance peoples' information sets. We note that we have also not controlled in a systematic way for changes in information which individuals hold between treatments 3 and 4: individuals may

\footnotetext{
${ }^{13}$ For examples of laboratory experiments see Hsee (2000), Kahneman and Knetsch 1993, Leier and Pruckner 2009 and Do et al (2008)
} 
have been exposed to many more environmental "good causes" or learnt more about the Peak District in the period between these two sessions, which caused them to revise their preferences or attitudes. Both additional information and "time to think" have been shown to change WTP in other workshop approaches to environmental valuation (MacMillan et al, 2003; MacMillan et al, 2006). However, diaries were kept between the workshops and no significant additional information was observed for those individuals who returned the diaries (other than that which would be expected from those living near or in a national park such as occasional visits - which were generally observed by the individuals as not outstanding in comparison to their usual usage of the resource).

It is also true that economic conditions changed during the $4^{\text {th }}$ quarter of 2007 and the first quarter of 2008 , in particular consumer spending slowed significantly (compared to 2007 Q3) possibly as a result of the credit crunch and past interest rates rises feeding through to consumption decisions (ONS 2008). Changes to consumer spending behaviour during the time between the first and second workshop would be expected to impact upon WTP for environmental goods in the same way it would for any other goods. This perhaps explains the result of a larger tax coefficient in the $4^{\text {th }}$ treatment. We note that whilst the values obtained in Treatment 2 are at the "point of consumption" in terms of the levels of each attribute in the choice experiment, they do not relate to real outcomes where individuals have actually paid a higher tax, and then waited for different environmental qualities to emerge. However, it is clear that location and timing of preference elicitation activities has an impact upon our estimates of preference.

The use of environmental valuation methods is becoming more and more common in the provision of an "evidence base" for policy development in many areas of public decision-making (Hanley and Barbier, 2009). The use of on-site surveys is often adopted for some of this policy relevant research (see for example the work reported in Hynes et al, 2013, and Christie et al, 2007). The use of "moment of consumption" measures of value would be particularly appropriate where onsite user fees are paid for use of a resource such as mountain bike trails or fishing in canals. With the increased use of ecosystem service framework in policy analysis and the growing interest in Payment for Ecosystem Service schemes, the use of onsite surveys is indeed likely to increase as identification of divergence in values for locations with different levels of ecosystem services will require localised surveys (Glenk et al, 2014). Equally where comparison of values across different groups (local residents and visitors or users and non users for example) is required for policy analysis the current research 
suggests that the use of onsite surveys for one group and off site surveys for the other may generate differnces in results which are not simply reflections on given differences in individual preferences. Indeed it is possible that identification of "insider outsider dichotomy" (Jones et al 2000) is compounded by differences in elicitation context where these are not held constant across the different populations. Where resources are funded from general taxation the use of on-site surveys may give over-estimates of WTP (assuming non significance of the price attribute in the second treatment relates to insufficiently high price levels) and policy makers may wish to consider the value people would place whilst at the ballot box (so valuing goods offsite) in deciding how to elicit preferences for costly changes to environmental management. Finally, we note that "moment of consumption" valuations are impossible or very difficult for an important class of public goods where non-use values dominate total value - such as protection of deep-sea biodiversity (Jobstvogt et al, 2014).

Our results cannot be taken as indicative of failures in the discrete choice experiment methodology. However, from a policy perspective, it is clear that the specific context in which these experiments are conducted does matter. Our results also raise questions over the use of cost-benefit analysis when some of the benefits (or costs) are measured at the moment of consumption, and other values are based on anticipated or remembered utility. 


\section{References}

Alvarez-Farizo B., and Hanley N. (2006) Improving the process of valuing non-market benefits: combining citizens' juries with choice modelling. Land Economics, 82 (3), 465-478.

Armsworth P, Acs S, Dallimer M, Gaston K, Hanley N and Wilson P (2012) "The costs of simplification in conservation programmes" Ecology Letters, Volume 15, Issue 5, Pages: 406-414.

Bateman I., Munro A., Rhodes B., Starmer C. and Sugden R. (2000) A Test of the Theory of ReferenceDependent Preferences. In Choices, Values and Frames, Kahneman D and Tversky A eds. Cambridge: Cambridge University Press.

Bentham, J. (1789) An Introduction to the Principles of Morals and Legislation (http://www.econlib.org/library/Bentham/bnthPML2.htm)

Beshears, J., Choi, J.J., Laibson, D., Madrian, B.C. (2008) How are preferences revealed?, Journal of Public Economics, 92, 1787-1794.

Bliem M., Getzner M., Rodiga-Labnig P. (2012) Temporal stability of individual preferences for river restoration in Austria using a choice experiment. Journal of Environmental Management, 103, 65-73

Bonaiuto M, Carrus G, Martorella H, Bonnes M (2002) Local identity processes and environmental attitudes in land use changes: the case of natural protected areas. Journal of Economic Psychology 23:631-653

Brickman and Campbell (1971) Hedonic Relativism and Planning the Good Society. Adaptation Level Theory: A Symposium, M.H. Apley, ed., New York: Academic Press, 1971, pp 287-302.

Bullock C.H. and Kay J. (1997) Preservation and change in the upland landscape: The public benefits of grazing management. Journal of Environmental Planning and Management 40(3): 315-334

Campbell, D. (2007). Willingness to Pay for Rural Landscape Improvements: Combining Mixed Logit and Random-Effects Models. Journal of agricultural economics, 58(3), 467-483.

Christie M, Hanley N and Hynes S (2007) Valuing Enhancements to Forest Recreation using Choice Experiment and Contingent Behaviour Methods Journal of Forest Economics, 13 (2-3), 75-102. 
Colombo S, Calatrava-Requena J \& Hanley N (2007) Testing choice experiment for benefit transfer with preference heterogeneity, American Journal of Agricultural Economics. 89 (1), pp. 135-151.

Czajkowski M., LaRiviere J. and Hanley N. (2013) "The effects of experience on preference uncertainty: : Theory and Empirics for Public and Quasi-Public Goods" Paper to the AARES conference, Sydney, February 2013.

Dallimer M., Tinch D., Acs S., Hanley N., Southall H.R., Gaston K.J. and Armsworth P.R. (2009) 100 years of change: examining agricultural trends, habitat change and stakeholder perceptions through the $20^{\text {th }}$ century. Journal of Applied Ecology, 46, 2, 334-343.

Do A.M., Rupert A.V. and Wolford, G. (2008). Evaluation of pleasurable experiences: The peak - end rule. Psychonomic Bulletin and Review 15 (1)

Dunn E., Gilbert D., Wilson T. (2003) Location, location, location: the misprediction of satisfaction in housing lotteries. Personality and Social Psychology Bulletin, 29 (11): 1421-1432.

Edgewoth F.Y. (1879) The Hedonical Calculus, Mind, 4 (15) 394-408.

Gilbert D.T. and Ebert J.E.J. (2002) Decisions and revisions: The affective forecasting of changeable outcomes. Journal of Personality and Social Psychology. 82:503-514

Gilbert D. T., Lieberman M. D., Morewedge C. K., \& Wilson T. D. (2004). The peculiar longevity of things not so bad. Psychological Science, 15, 14-19.

Glenk K., Schaafsma M., Moxey A., Martin-Ortega J. and Hanley N. (2014) “A framework for valuing spatiallytargetted peatland restoration" Ecosystem Services, in press.

Gomez-Limon J. and Fernandez J.V.D. (1999) Changes in use and landscape preferences on the agricultural livestock landscape of the central Iberian Peninsula (Madrid, Spain). Landscape and Urban Planning. 44:165175

Grammatikopoulou, I., E. Pouta, M. Salmiovirta, and K. Soini. (2012). Heterogeneous preferences for agricultural landscape improvements in southern Finland. Landscape and Urban Planning, 107(2), 181-191. 
Hanley N. and Shogren J. (2005) Is cost-benefit analysis anomaly-proof? Environmental and Resource Economics, $32(1), 13-34$.

Hanley N, MacMillan DC and Patterson I (2003) Economics and the design of nature conservation policy: A case study of wild goose conservation in Scotland using choice experiments. Animal Conservation 6: 123-129 Hanley N, Ready R, Colombo S, Watson F, Stewart M and Bergmann EA (2009) "The impacts of knowledge of the past on preferences for future landscape change" Journal of Environmental Management, Volume 90, Issue 3, Pages 1404-1412

Hanley N and Barbier EB (2009) Pricing Nature: Cost Benefit Analysis and Environmental Policy. Cheltenham: Edward Elgar.

Hanley, N., Colombo, S., Kristrom, B. and Watson, F., (2009) Accounting for negative, zero and positive willingness to pay for landscape change. Journal of Agricultural Economics 60(1): 1-16

Hanley N, Acs S., Dallimer M, Graves A, Morris J, Gaston K and Armsworth P. (2012) "Farm-scale ecological and economic impacts of agricultural change in the uplands." Land Use Policy, 29 (3), 587-597.

Helson H. (1964) Adaptation-Level Theory: An Experimental and Systematic Approach to Behaviour, Harper \& Row, New York

Hensher D., Rose J. and Greene W. (2005) Applied Choice Analysis: a primer. Cambridge: Cambridge University Press.

Hoehn, J. P., Lupi, F., and Kaplowitz, M. D., 2010. Stated Choice Experiments with Complex Ecosystem Changes: The Effect of Information Formats on Estimated Variances and Choice Parameters. Journal of Agricultural and Resource Economics, 35(3):568-590.

Hynes S., Hanley N. and Scarpa, R. (2008) "Effects on Welfare Measures of Alternative Means of Accounting for Preference Heterogeneity in Recreational Demand Models", American Journal of Agricultural Economics, (90) 4, 1011-1027. 
Hynes S., Hanley N. and Tinch D. (2013) “Valuing improvements to coastal waters using choice experiments: an application to revisions of the EU Bathing Waters Directive" Marine Policy, 40: 137-144.

Jobstvogt N., Hanley N., Hynes S., Kenter J. and Witte U. (2014) "Twenty thousand sterling under the sea: estimating the economic value of protecting deep sea biodiversity" Ecological Economics, 97: 10-19.

Jones C.D., Patterson M.E., Hammitt W.E. (2000) Evaluating the construct viability of sense of belonging as a measure of landscape perception. Journal of Leisure Research, 32: 383-395

Kahneman D., Wakker P. and Sarin R. (1997), Back to Bentham? Explorations of experienced utility. Quarterly Journal of Economics 112; 375-405.

Kahneman D. (2003) Maps of Bounded Rationality: Psychology for Behavioural Economics. The American Economic Review. $1449-1475$

Kahneman D., Kreuger A., D. Schkade, Schwarz N. and Stone A. (2004), 'A Survey Method for Characterizing Daily Life Experience: The Day Reconstruction Method', Science 306: 1776-1780.\# Kahneman D. and SugdenR. (2005) Experienced utility as a standard of policy design. Environmental and Resource Economics, 32: 161-181

Kahneman D. and Tversky A. (2000) Choices, values and frames. In Choices, Values and Frames, Kahneman D and Tversky A eds. Cambridge: Cambridge University Press.

Kaltenborn B.P. and Bjerke T. (2002) The relationship of general life values to attitudes towards large carnivores. Human Ecology Review 9: 55-61

Krinsky I. and Robb A.L. (1986) On approximating the statistical properties of elasticities. Review of Economic Statistics 68(4):715-719

Liebe U., Meyerhoff J. and Hartje V. (2012) Test-retest reliability of choice experiments in environmental valuation. Environmental \& Resource Economics 53, 389-407

Loewenstein G., O'Donoghue T. and Rabin M. (2003) Projection Bias in Predicting Future Utility. The Quarterly Journal of Economics 118 (4), 1209-1248. 
Loomes G. (2006) (How) Can we value health, safety and the environment? Journal of Economic Psychology 27: 713-736.

MacMillan D., Philip L., Hanley N. and Alvarez-Farizo B. (2003) Valuing non-market benefits of wild goose conservation: a comparison of interview and group-based approaches. Ecological Economics, 43, 49-59.

MacMillan D., Hanley N. and Lienhoop N. (2006) Contingent valuation: environmental polling or preference engine? Ecological Economics, 60 (1), 299-307.

Marshall A. (1920) Principles of Economics. $8^{\text {th }}$ Edition London: Macmillan and Co., Ltd.

http://www.econlib.org/library/Marshall/marP11.htm

Munro A and Hanley N "Information, Uncertainty and Contingent Valuation" in Bateman, I.J. and Willis, K.G. (eds.) Contingent Valuation of Environmental Preferences: Assessing Theory and Practice in the USA, Europe, and Developing Countries. Oxford University Press.

Natori Y and Chenoweth R (2008) Differences in rural landscape perceptions and preferences between farmers and naturalists. Journal of Environmental Psychology 28(3): 250-267

ONS (Office for National Statistics) (2008) Economic \& Labour Market Review 2 (4) April 2008

Rabonilaza M and Dachary-Bernard J. (2007) Land-use planning and public preferences: What can we learn from Choice Experiments method? Landscape and Urban Planning 83: 318-326

Redelmeier D.A. and Kahneman D. (1996) Patients' memories of painful medical treatments: Real-time and retrospective evaluations of two minimally invasive procedures. Pain, 66, 3-8.

Robson A. and Samuelson L. (2010) The Evolution of Decision and Experienced Utilities Cowles Foundation Discussion Paper No. 1678.

Scarpa R., Ferrini S. and Willis K. (2005) Performance of Error Component models in Choice Experiments in Scarpa R. and Alberini A (eds) Applications of Simulation Methods in Environmental and Resource Economics. Dordrecht: Springer. 
Scarpa R., Thiene M. and Train K. (2008) Utility in WTP space: a tool to address confounding random scale effects in destination choice to the Alps. American Journal of Agricultural Economics, 90, 994-1010.

Scitovsky T. (1976). The Joyless Economy: The Psychology of Human Satisfaction. Oxford: Oxford University Press

Stone A. A., Shiffman S. S. and DeVries M. (1999) Rethinking Self-report Assessment Methodologies, in D.

Kahneman, E. Diener and N. Schwarz, eds., Well-Being: The Foundations of Hedonic Psychology (pp. 26-39). New York: Cambridge University Press.

Tversky A. and Kahneman D. (1982) "Availability: a heuristic for judging frequency and probability" in Judgement under Uncertainty: heuristics and biases. Edited by D. Kahneman., P. Slovic and A. Tversky. Cambridge University Press.

Tversky A., Sattath S. and Slovic P. (2000) Contingent Weighting in Judgement and Choice. In Choices, Values and Frames, Kahneman D and Tversky A eds. Cambridge: Cambridge University Press.

Van den Berg A.E., Velk C.A.J. and Coeterier J.F. (1998) Group differences in the aesthetic evaluation of nature development plans: A multilevel approach. Journal of Environmental Psychology, 18:141-157 
Table 1: Sample choice card

\begin{tabular}{|c|c|c|c|}
\hline & A & B & Do Nothing \\
\hline $\begin{array}{l}\text { Moorland - intensity of } \\
\text { management }\end{array}$ & $\begin{array}{l}\text { Less Intensive - less } \\
\text { sheep and burning. } \\
\text { More bird species }\end{array}$ & No Change in Intensity & $\begin{array}{l}\text { More Intensive - } \\
\text { more sheep and } \\
\text { burning }\end{array}$ \\
\hline $\begin{array}{l}\text { Moorland Fringe - intensity } \\
\text { of management }\end{array}$ & $\begin{array}{l}\text { Less Intensive- less } \\
\text { sheep and burning. } \\
\text { More bird species }\end{array}$ & $\begin{array}{l}\text { Less Intensive- less } \\
\text { sheep and burning. } \\
\text { More bird species }\end{array}$ & $\begin{array}{l}\text { More Intensive - } \\
\text { more sheep, fertilizer } \\
\text { and drainage }\end{array}$ \\
\hline $\begin{array}{l}\text { Valley Bottom Farmland - } \\
\text { intensity of management }\end{array}$ & No Change in Intensity & $\begin{array}{l}\text { Less Intensive - less } \\
\text { sheep and fertiliser. } \\
\text { More bird species }\end{array}$ & $\begin{array}{l}\text { More Intensive - } \\
\text { more sheep and } \\
\text { fertilizer. }\end{array}$ \\
\hline Footpath Network & Improved & Degraded & Degraded \\
\hline Tax Cost & f5 & $£ 55$ & $£ 0$ \\
\hline $\begin{array}{l}\text { Please tick the option you } \\
\text { prefer. }\end{array}$ & $\square$ & $\square$ & $\square$ \\
\hline
\end{tabular}


Table 2 Error component logit model co-efficients for each treatment.

(Coefficients found to be statistically significant at the $95 \%$ level are indicated in bold).

\begin{tabular}{|c|c|c|c|c|c|c|c|c|c|c|}
\hline \multirow{2}{*}{$\begin{array}{l}\text { Treatment } \\
\text { Mean } \\
\text { Values }\end{array}$} & \multicolumn{2}{|c|}{1 (Off Site) } & \multicolumn{2}{|c|}{2 (On Site) } & \multicolumn{2}{|c|}{3 (Off Site) } & \multicolumn{2}{|c|}{4 (Off Site) } & \multicolumn{2}{|c|}{5 (Pooled) } \\
\hline & Coef. & S.e. & Coef. & S.e. & Coef. & S.e. & Coef. & S.e. & Coef. & S.e. \\
\hline Const & 0.031 & 2.202 & -2.661 & 1.274 & -1.979 & 2.188 & -1.577 & 2.823 & -1.92 & 1.29 \\
\hline MoorLI & -0.097 & 0.164 & -0.506 & 0.212 & -0.155 & 0.175 & -0.238 & 0.310 & -0.219 & 0.0903 \\
\hline MoorMI & -0.995 & 0.309 & -0.516 & 0.253 & -0.593 & 0.245 & -1.097 & 0.327 & -0.904 & 0.115 \\
\hline FringeLI & -0.512 & 0.192 & -0.605 & 0.206 & -0.209 & 0.181 & -0.516 & 0.282 & -0.494 & 0.102 \\
\hline FringeMI & -0.191 & 0.236 & -0.010 & 0.206 & -0.313 & 0.207 & -0.238 & 0.259 & -0.206 & 0.0972 \\
\hline FarmLI & -0.643 & 0.258 & -0.531 & 0.247 & -0.342 & 0.282 & -0.494 & 0.301 & -0.591 & 0.119 \\
\hline FarmMI & -1.219 & 0.266 & -0.741 & 0.289 & -0.617 & 0.313 & -1.242 & 0.385 & -1.12 & 0.197 \\
\hline PathD & -0.018 & 0.292 & 0.386 & 0.215 & 0.139 & 0.228 & -0.411 & 0.233 & -0.0376 & 0.119 \\
\hline Pathl & 0.509 & 0.221 & -0.126 & 0.274 & 0.323 & 0.290 & 0.415 & 0.325 & 0.386 & 0.117 \\
\hline Tax & -0.026 & 0.010 & -0.003 & 0.005 & -0.018 & 0.006 & -0.038 & 0.007 & -0.0258 & 0.0037 \\
\hline Female & 2.797 & 0.929 & 1.410 & 0.761 & 1.403 & 1.126 & 2.381 & 1.306 & 2.69 & 0.672 \\
\hline Local & -2.897 & 1.551 & 0.434 & 0.803 & -0.683 & 1.103 & -0.103 & 1.521 & -0.545 & 0.708 \\
\hline Age & 0.035 & 0.031 & 0.070 & 0.021 & 0.058 & 0.036 & 0.019 & 0.034 & 0.0554 & 0.0218 \\
\hline Error & & & & & & & & & & \\
\hline Sigma & -2.017 & 0.540 & -1.607 & 0.286 & -2.609 & 0.491 & -3.000 & 0.620 & 2.87 & 0.444 \\
\hline $\begin{array}{l}\text { Scale } \\
\text { Parameters }\end{array}$ & 1.00 & & $0.518^{+}$ & 0.097 & 0.837 & 0.136 & 1.13 & 0.168 & 1.00 & \\
\hline $\mathbf{N}$ & 654 & & 652 & & 655 & & 635 & & 2596 & \\
\hline LL & -718.49 & & -716.30 & & -719.59 & & -697.62 & & -2252.1 & \\
\hline Pseudo $R^{2}$ & 0.24 & & 0.17 & & 0.23 & & 0.25 & & 0.22 & \\
\hline
\end{tabular}

+ . Significantly different from 1. 
Table 3. Explanation of variable abbreviations and coding in table 2

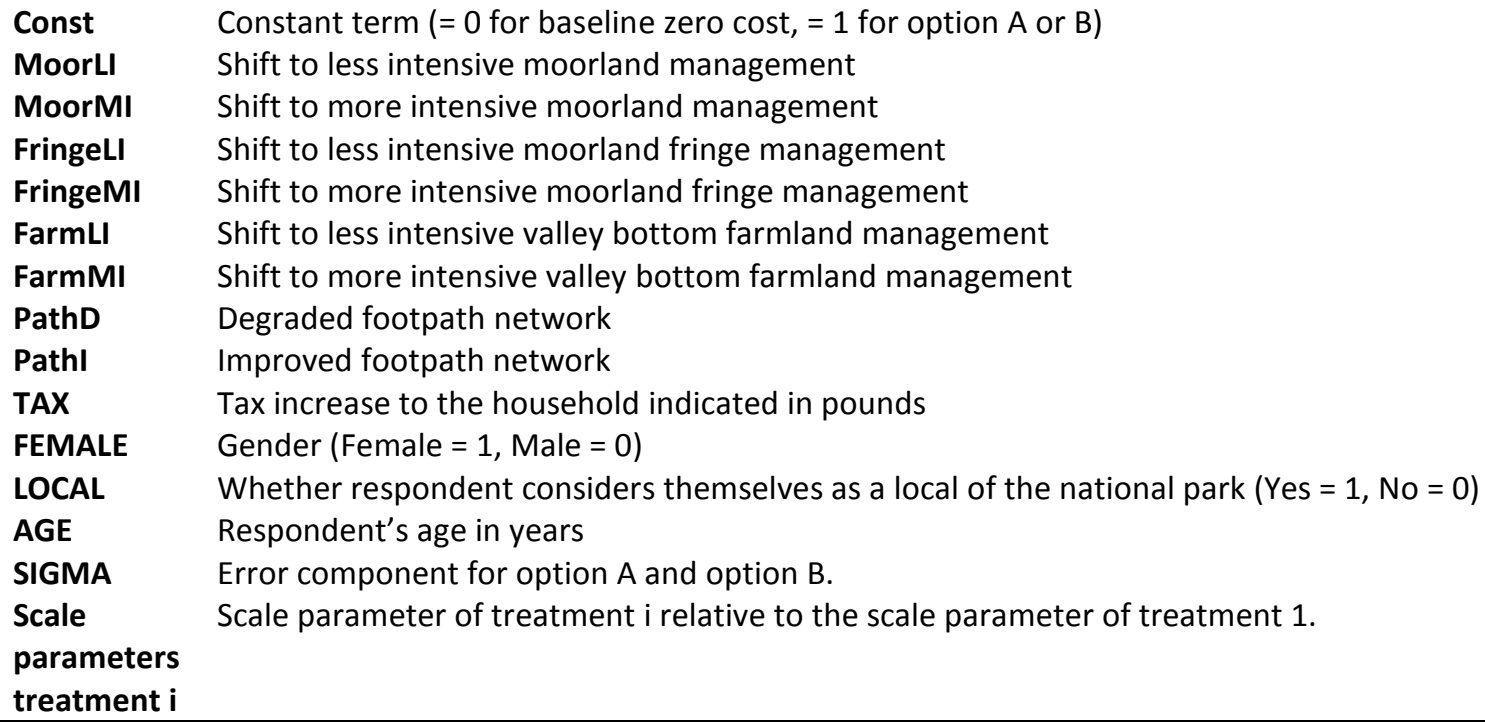


Table 4: WTP for a change from the current level of provision.

( $f$ per household per year)

\begin{tabular}{|c|c|c|c|c|}
\hline Variable & $\begin{array}{ll}\text { Treatment } 1 & \text { Off } \\
\text { site } & \end{array}$ & $\begin{array}{l}\text { Treatment } 2 \text { On } \\
\text { Site }\end{array}$ & $\begin{array}{ll}\text { Treatment } 3 & \text { Off } \\
\text { site } & \end{array}$ & $\begin{array}{l}\text { Treatment } 4 \\
\text { Off site }\end{array}$ \\
\hline Moor LI & $\begin{array}{l}-£ 4.8 \\
(f-27.2 \quad 12.8)\end{array}$ & N.A & $\begin{array}{l}-f 8.9 \\
(f-35.2 \quad 13.5)\end{array}$ & $\begin{array}{l}-f 6.3 \\
(f-22.9 \quad 10.3)\end{array}$ \\
\hline Moor MI & $\begin{array}{l}-£ 45.7 \\
(£-121.6-18.3)\end{array}$ & N.A & $\begin{array}{l}-£ 37.0 \\
(£-92.28 .2)\end{array}$ & $\begin{array}{l}-£ 29.7 \\
(f-54.4-11.1)\end{array}$ \\
\hline Fringe LI & $\begin{array}{l}-£ 25.1 \\
(£-77.0-4.5)\end{array}$ & N.A & $\begin{array}{l}-£ 12.4 \\
(£-39.49 .5)\end{array}$ & $\begin{array}{l}-£ 13.6 \\
(£-26.95 .8)\end{array}$ \\
\hline Fringe MI & $\begin{array}{l}-£ 13.2 \\
(£-68.29 .2)\end{array}$ & N.A & $\begin{array}{l}-£ 21.6 \\
(f-73.7 \quad 3.2)\end{array}$ & $\begin{array}{l}-£ 7.3 \\
(£-24.2 \quad 5.8)\end{array}$ \\
\hline Farm LI & $\begin{array}{l}-£ 36.6 \\
(f-135.9-2.2)\end{array}$ & N.A & $\begin{array}{l}-£ 24.7 \\
(f-95.5 \quad-8.2)\end{array}$ & $\begin{array}{l}-£ 14.4 \\
(£-37.8 \quad 1.4)\end{array}$ \\
\hline Farm MI & $\begin{array}{l}-£ 57.9 \\
(£-159.3-25.3)\end{array}$ & N.A & $\begin{array}{l}-£ 37.4 \\
(f-94.9 \quad-1.7)\end{array}$ & $\begin{array}{l}-£ 32.8 \\
(£-50.7-14.6)\end{array}$ \\
\hline Path Degraded & $\begin{array}{l}f 8.3 \\
(f-13.177 .4)\end{array}$ & N.A & $\begin{array}{l}£ 13.5 \\
(f-12.174 .8)\end{array}$ & $\begin{array}{l}f-10.7 \\
(f-20.80 .9)\end{array}$ \\
\hline Path Improved & $\begin{array}{l}£ 25.8 \\
(£ 1.486 .8)\end{array}$ & N.A & $\begin{array}{l}£ 20.1 \\
(f-15.2 \quad 66.1)\end{array}$ & $\begin{array}{l}£ 11.0 \\
(£-7.428 .8)\end{array}$ \\
\hline
\end{tabular}

Figures in brackets are 95\% confidence intervals estimated by the bootstrapping method (Krinsky and Robb, 1986) Figures in bold are significant WTP at the $95 \%$ level.

Notes: MoorLI is less intensive management of moorland areas; MoorMI is more intensive management of these areas. FringleLI is less intensive management of the moorland fringe, FringeMI is more intensive management of these areas. FarmLI is less intensive management of valley bottom farmland; FarmMI is more intensive management of these areas. 